\title{
O gênero Bulbophyllum Thouars (Orchidaceae, Epidendroideae) no Parque Nacional da Chapada dos Veadeiros, Goiás, Brasil
}

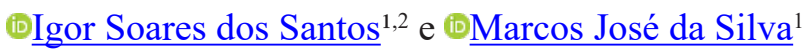

Recebido: 15 setembro 2018; aceito: 26 agosto 2019

Como citar: Santos, I.S. \& Silva, M.J. 2019. O gênero Bulbophyllum Thouars (Orchidaceae, Epidendroideae) no Parque Nacional da Chapada dos Veadeiros, Goiás, Brasil. Hoehnea 46: e872018. http://dx.doi.org/10.1590/2236-8906-87/2018.

ABSTRACT - (The genus Bulbophyllum Thouars (Orchidaceae, Epidendroideae) in the Chapada dos Veadeiros National Park, Goiás State, Brazil). Bulbophyllum is one of the largest genera of Angiosperms with 2.200 species worldwide. In Brazil, there occur 60 species of which ten are recorded in the state of Goiás. The lack of taxonomic studies including Bulbophyllum in the Cerrado Phytogeographical Domain (CPD) led us to study the genus in the Chapada dos Veadeiros National Park, one of the most preserved areas of the Brazilian CPD. Six species were recorded: B. adiamantinum, B. ciluliae, B. epiphytum, $B$. exaltatum, B. plumosum, and B. rupicolum. Bulbophyllum adiamantinum is a new record for Goiás. The species are described, illustrated in their diagnostic characters and allow their recognition. Comments on their distribution, ecological preferences, morphological affinities, and phenology are provided. Additionally, a dichotomous key is also presented.

Keywords: Cerrado, diversity, flora, taxonomy

RESUMO - (O gênero Bulbophyllum Thouars (Orchidaceae, Epidendroideae) no Parque Nacional da Chapada dos Veadeiros, Goiás, Brasil). Bulbophyllum é um dos maiores gêneros de Angiospermas, com 2.200 espécies em todo o mundo. No Brasil ocorrem 60 espécies, das quais 10 são registradas para o estado de Goiás. Diante da carência de estudos taxonômicos sobre este gênero no Domínio Fitogeográfico do Cerrado (DFC), objetivou-se estudá-lo no Parque Nacional da Chapada dos Veadeiros, uma das áreas relictuais mais preservadas do DFC no Brasil. Foram registradas seis espécies: B. adiamantinum, B. ciluliae, B. epiphytum, B. exaltatum, B. plumosum e B. rupicolum. Bulbophyllum adiamantinum representa um novo registro para o estado de Goiás. As espécies seguem descritas e ilustradas em seus caracteres diagnósticos e que permitem o reconhecimento das mesmas. Comentários quanto a distribuição, preferências ambientais, relações morfológicas e fenologia são fornecidos, bem como uma chave dicotômica para identificação específica.

Palavras-chave: Cerrado, diversidade, flora, taxonomia

\section{Introdução}

Bulbophyllum Thouars compreende cerca de 2.200 espécies (Gravendeel et al. 2014), é considerado o segundo maior gênero dentre as Angiospermas (Frodin 2004), e um dos maiores e mais complexos taxonomicamente entre as Orchidaceae (Sieder et al. 2007). O gênero possui distribuição Pantropical, com maior diversidade no sudeste Asiático (ca. $1.600 \mathrm{spp}$ ). Por outro lado, nos Neotrópicos está representado por 70 espécies, 60 das quais presentes no Brasil (Smidt \& Borba 2007, Mancinelli \& Smidt 2012, Vermeulen 2014).
A taxonomia das espécies neotropicais de Bulbophyllum recebeu importante contribuição com a revisão de Smidt (2007), e mais recentemente, Mancinelli \& Smidt (2012) apresentaram um tratamento taxonômico para a Região Sul do Brasil. Além disso, novas espécies foram propostas para Minas Gerais (ex.: Mota et al. 2009, Smidt \& Borba 2007, 2008, 2009, Campacci 2009, 2010) e Espírito Santo (Chiron \& Castro Neto 2009), o que significa que ainda há muito a ser descoberto para o gênero no Brasil.

No Estado de Goiás, menções a espécies de Bulbophyllum são encontradas no estudo de Hall

1. Universidade Federal de Goiás, Instituto de Ciências Biológicas, Departamento de Botânica, Laboratório de Morfologia e Taxonomia Vegetal, Alameda Ingá, Quadra A, Campus Samambaia, 74001-970 Goiânia, GO, Brasil

2. Autor para correspondência: igorsoares1237@gmail.com 
et al. (2013) tratando das Orchidaceae no município de Caldas Novas, e na listagem florística elaborada por Mendonça et al. (2007) para a região da Chapada dos Veadeiros.

Diante do exposto, objetivou-se o tratamento taxonômico das espécies de Bulbophyllum ocorrentes no Parque Nacional da Chapada dos Veadeiros, Goiás, Brasil. As espécies seguem descritas, ilustradas, comentadas quanto a sua distribuição geográfica, preferências ambientais, relações morfológicas e fenologia, e contrastadas por meio de uma chave de identificação.

\section{Material e métodos}

O Parque Nacional da Chapada dos Veadeiros (PNCV) localiza-se no nordeste do Estado de Goiás (figura 1a), apresenta uma área de 65.510 ha, abrangendo os municípios Alto Paraíso de Goiás, Cavalcante, Teresina de Goiás (ao norte) e Colinas do Sul (a oeste), entre $13^{\circ} 50^{\prime}-14^{\circ} 12^{\prime} \mathrm{S}$ e $47^{\circ} 24^{\prime}-47^{\circ} 58^{\prime} \mathrm{W}$. O PNCV compreende um complexo montanhoso com heterogêneos tipos de solos e relevos, os quais lhe conferem variadas paisagens. Sua vegetação inclui distintas fitofisionomias (ex.: campo limpo, sujo ou rupestre, cerrados densos, ralos, típicos e rupestres, matas ciliares ou matas de galeria, veredas e florestas estacionais (figura 1b-e). Seu clima é o CWbl com precipitação média anual entre 1.500 e $1.750 \mathrm{~mm}$, temperatura entre $24-26^{\circ} \mathrm{C}$ e a altitude desde 800 até 1.676 metros (Felfili et al. 2007, Munhoz \& Proença 2008).

A coleta do material botânico foi feita entre julho de 2016 e outubro de 2018 segundo as recomendações de Mori et al. (1989). Flores e frutos foram acondicionados em álcool etílico $70 \%$ para auxiliar na identificação, no estudo morfológico comparativo e nas ilustrações das espécies. Todo o material coletado foi incorporado ao acervo do Herbário UFG da Universidade Federal de Goiás.

As espécies foram identificadas utilizando bibliografia especializada (e.g., Brade 1951, Smidt 2007, Verola 2002 e Mancinelli 2011), por comparações com coleções dos Herbários CEN, UB, UFG ou digitalizadas, previamente identificadas por especialistas, provenientes dos Herbários ALCB, AMES, BHCB, CEPEC, EAC, F, HCF, HUEFS, IAN, K, MBM, MO, NY, P, RB, SP, UEC e US (acrônimos segundo Thiers 2018), incluindo coleções tipo. As ilustrações das espécies foram feitas pelo primeiro autor com o auxílio de um estereomicroscópio Zeiss com câmara clara acoplada e constam de caracteres relevantes para o reconhecimento das mesmas. Informações sobre a distribuição geográfica das espécies foram obtidas por meio de consulta a literatura especializada supracitada, a partir de coletas próprias ou retiradas dos rótulos de exsicatas das coleções consultadas, incluindo aquelas citadas como material examinado adicional. A terminologia adotada nas descrições das espécies fundamentou-se nos trabalhos utilizados para a identificação das mesmas. O mapa da área de estudo foi confeccionado no software QGIS (Quantum GIS Development Team) version 2.8.1.).

\section{Resultados e Discussão}

Bulbophyllum no PNCV está representado por seis espécies, de um total de dez citadas por BFG (2015) para o Estado de Goiás. As mesmas crescem como rupícolas ou epífitas, ou ambas, em geral, associadas ao cerrado rupestre, campos rupestres, matas ciliares ou de galeria. Quanto a conservação, de acordo com Smidt (2007), as espécies supracitadas encontram-se na categoria "Não ameaçadas".

Essas espécies encontram-se arranjadas em três seções: $B$. sect. Didactyle (Lindl.) Cogn. ( $B$. exaltatum), B. sect. Micranthae Barb. Rodr. (B. adiamantinum, B. epiphytum e $B$. rupicolum) e $B$. sect. Xiphizusa Rchb. f. (B. ciluliae e B. plumosum), respectivamente, sendo $B$. adiamantinum um novo registro para a flora goiana, pois, até este estudo, era uma espécie endêmica de Minas Gerais.

Os resultados deste estudo contribuem, sobremaneira, com o conhecimento da diversidade taxonômica do gênero Bulbophyllum, ampliando a riqueza do mesmo no estado de Goiás, incrementando o acervo dos herbários citados no texto com novas coleções e destacando a riqueza florística do Parque Nacional da Chapada dos Veadeiros, uma das áreas relictuais de preservação permanente mais importantes do Brasil.

Bulbophyllum Thouars, Hist. Orchid. 93. 1822.

Ervas rupícolas ou epífitas; rizomas longos ou curtos; pseudobulbos unifoliados, globosos, piriformes ou ovoides com ápices simétricos ou assimétricos e facetas angulosas. Folha com lâmina plana ou cilíndrica, carnosa ou coriácea, sulcada ou não longitudinalmente, constricta basalmente. Racemos laterais partindo da base do pseudobulbo, eretos ou curvos distalmente, 

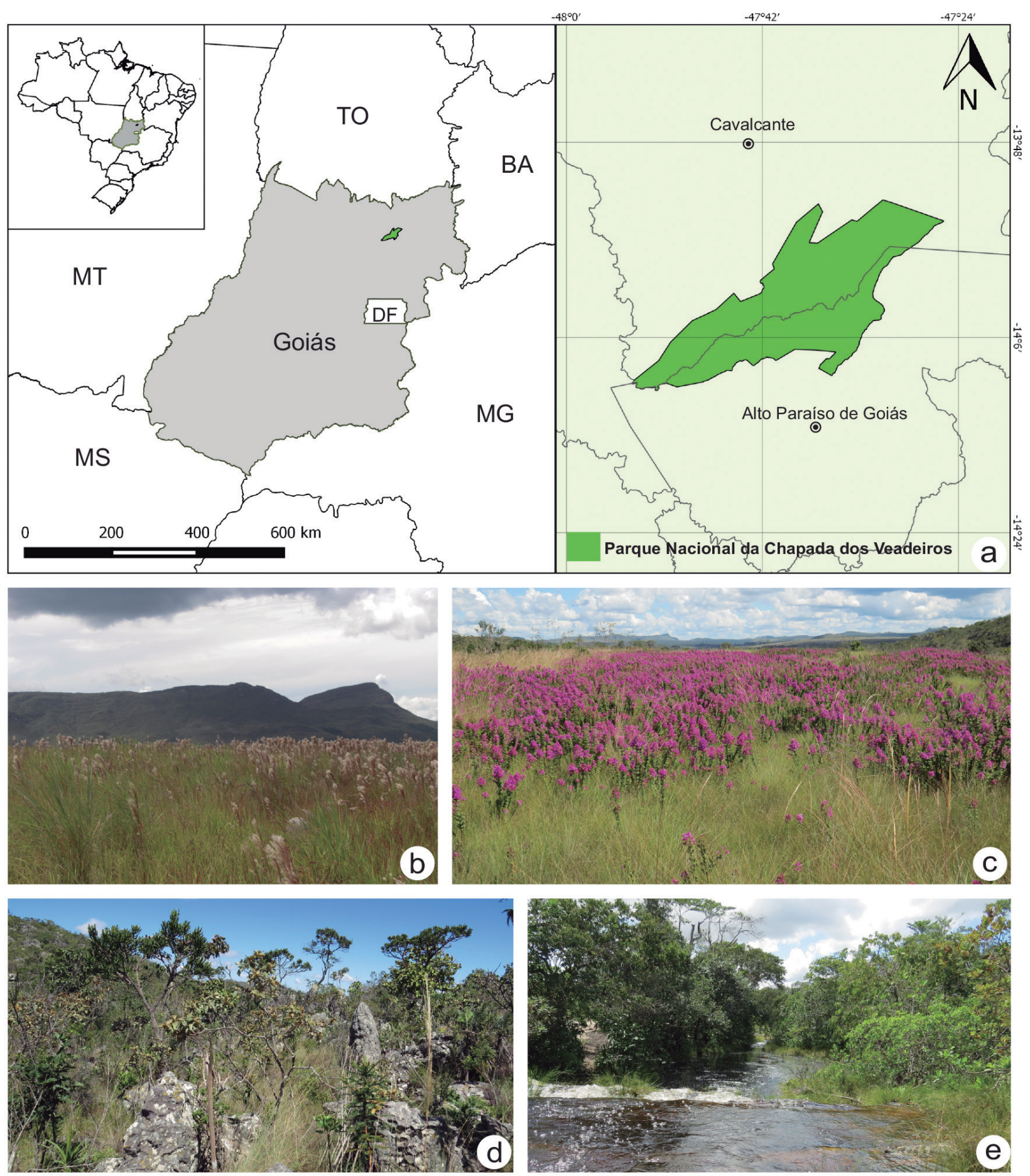

Figura 1. Localização e fitofisionomias da área de estudo (Parque Nacional da Chapada dos Veadeiros, PNCV). a. Mapa do Brasil destacando o Estado de Goiás e a área de estudo. b-e. Fitofisionomias. b. Campo limpo. c. Campo sujo. d. Cerrado rupestre. e. Mata ciliar. BA: Bahia, DF: Distrito Federal, MG: Minas Gerais, MT: Mato Grosso, MS: Mato Grosso do Sul, TO: Tocantins.

Figure 1. a. Location of the study area and the phytophysiognomies (Chapada dos Veadeiros National Park, PNCV). a. Map of Brazil highlighting the State of Goiás and a study area. b-e. Phytophysiognomies. b. Campo limpo. c. Campo sujo. d. Rocky field. e. Riparian forest. BA: Bahia, DF: Distrito Federal, MG: Minas Gerais, MT: Mato Grosso, MS: Mato Grosso do Sul, TO: Tocantins. 
com flores dísticas ou espiraladas com ou sem jugo, este último conspícuo ou inconspícuo. Sépalas livres ou laterais conatas, naviculares ou planas com cores e formas variadas; pétalas planas; o labelo inteiro ou trilobado, com os lobos laterais diferenciados ou não e com ou sem apêndices basais, calo e quilha carnosa na face abaxial. Coluna com estelídeos maiores ou menores que as anteras; dentes ausentes ou presentes; pé da coluna lobulado na base ou inteiro. Polinário com dois pares de polínias compactadas, inapendiculadas, dimórficas ou monomórficas, sobrepostas ou enfileiradas. Frutos do tipo cápsulas.

\section{Chave para as espécies do gênero Bulbophyllum ocorrentes no PNCV}

\section{Folhas planas}

2. Flores alternas ao longo da raque; lobo mediano do labelo espatulado

5. B. plumosum

2. Flores espiraladas ao longo da raque; labelo não espatulado

3. Pseudobulbo com ápice assimétrico; folhas oblongo-elípticas; flores brancas com máculas vináceas; pétalas com margem ciliada; labelo vináceo com máculas brancas; estelídeos não petaloides; polínias enfileiradas

4. B. exaltatum

3. Pseudobulbo com ápice simétrico; folhas ovais-elípticas; flores vináceas com máculas e estrias esverdeadas; pétalas sem a margem ciliada; labelo castanho-amarelado, não maculado; estelídeos petaloides; polínias sobrepostas 2. B. ciluliae

\section{Folhas cilíndricas}

4. Estelídeos dentiformes, flores branco-amareladas sem máculas vináceas

5. Pseudobulbo piriforme, região basal do labelo com margem serrilhada; pétalas lanceoladas sem nervura vinácea; lobo mediano do labelo elíptico-oboval 3. B. epiphytum

5. Pseudobulbo globoso, região basal do labelo com margem inteira; pétalas elíptico-lanceoladas com nervura vinácea; lobo mediano do labelo oblongo-oboval 6. B. rupicolum

4. Estelídeos falcados, flores amarelo-esverdeadas com máculas vináceas 1. B. adiamantinum

1. Bulbophyllum adiamantinum Brade, Arch. Jard. Bot. Rio de Janeiro 11: 79. 1951.

Figuras 2, 8 c-e

Erva rupícola e epífita. Rizoma 0,2-1,5 cm compr., entre os pseudobulbos. Pseudobulbo 0,4-3 ×0,3-3 cm, ovoide, ápice simétrico, castanho-amarelado, levemente arroxeado. Folha 1,4-11,3 × 0,1-0,6 cm, cilíndrica, pouco curvada, carnosa, não sulcada longitudinalmente, ápice agudo, verde-oliva. Racemo 7,2-31 cm compr., com 9-46 flores, curvo, laxo; pedúnculo 4,2-17,8 cm compr., raque $3-13,2 \mathrm{~cm}$ compr., pêndula. Brácteas, oval-lanceoladas, membranáceas, ápice agudo; as do pedúnculo 0,2-1,6 $\times 0,3-0,6 \mathrm{~cm}$; as florais $0,1-0,5 \times 0,1-0,2 \mathrm{~cm}$, vináceas. Flores 5,7-8 mm compr., espiraladas na raque, jugo presente, triangular, inconspícuo; ovário + pedicelo 0,7-2 × 1,6-2 mm, obcônico, verde-arroxeado. Sépalas 3-nervadas, pouco carnosas, glabras, ápice agudo, margem inteira, amarelo-esverdeadas com estrias e máculas vináceas; a dorsal 5-6 × 1,6-2,2 mm, ovallanceolada, margem vinácea; as laterais 5-6 × 2-2,5 $\mathrm{mm}$, triangulares, subfalcadas, unidas na base base formando um mento, margem vinácea. Pétalas 3,8-5,1 $\times 1,4-1,6 \mathrm{~mm}$, oval-lanceoladas, sésseis, 1-nervadas, membranáceas, base truncada, ápice agudo, margem levemente papilosa, amarelo-esverdeadas com uma estria vinácea central. Labelo 1,5-2,2 × 0,8-2,1 $\mathrm{mm}, 3$-lobado, carnoso, conspicuamente papiloso, vináceo, disco com sulco liso longitudinal, hipoquílo e epiquílo indiferenciados, ápice sub-revoluto; lobos laterais, inconspícuos, subdentiformes, vináceos; lobo mediano, oblongo, vináceo com papilas adensadas próximo ao ápice que é arredondado. Coluna 0,8-1,3 mm compr., papilosa ventralmente, branco-esverdeada; estelídeos presentes, ca. 0,3 $\mathrm{mm}$ compr., falcados, menores que a antera, ápice agudo, amarelo-esverdeados; dentes ausentes. Pé da coluna 0,4-0,6 mm compr. Antera 0,8-1 × 0,7-0,8 mm, oval, papilosa, ápice arredondado, amarela. Polínias ca. $1 \mathrm{~mm}$ compr., 4, dimórficas, sobrepostas, amarelas. Cápsulas 0,4-0,9 × 0,3-0,6 cm, ovoide-elípticas, não pendentes, verde-amareladas com máculas roxas.

Material examinado: BRASIL. GoIÁs: PNCV, Alto Paraíso de Goiás, no Cruzeiro, em cerrado rupestre, 1-VII-2017, fl., I.S. Santos et al. 077 (UFG); idem, cerca de $1 \mathrm{~km}$ do Morro do Japonês, cerca de 1,5 $\mathrm{km}$ da estrada, $14^{\circ} 02^{\prime} 11^{\prime \prime} \mathrm{S}, 47^{\circ} 32^{\prime} 18^{\prime \prime} \mathrm{W}, 1435 \mathrm{~m}$, em cerrado rupestre, 26-VIII-2017, fl., I.S. Santos et al. 218 (UFG); idem, 1401'54"S, 47³1'55"W, $1461 \mathrm{~m}$, 22-IX-2017, fl., I.S. Santos et al. 244 (UFG); idem, 

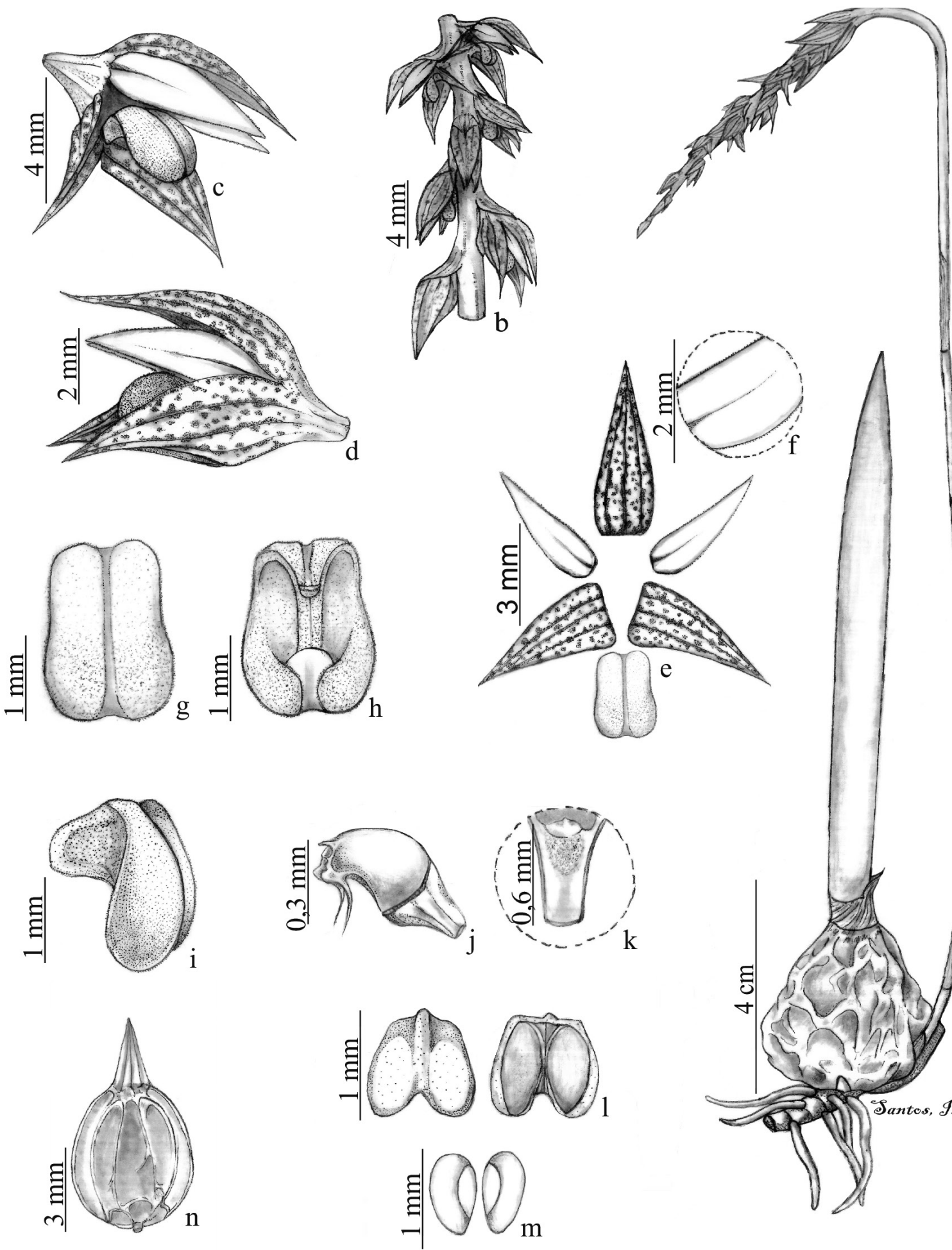
15-XII-2017, fl., I.S. Santos et al. 276 (UFG); idem, em campo rupestre, sobre rochas, 7-X-1972, fl., J.A. Rizzo 8427 (UFG).

Material examinado adicional: BRASIL. MinAS GeraIs: Diamantina, VI-1934, fl., A.C. Brade s.n (RB542557); Joaquim Felício, Serra do Cabral, em afloramento rochoso, 15-IX-2001, fl., C.F. Verola, J. Semir \& E.L. Borba s.n. (UEC122332).

Bulbophyllum adiamantinum até este estudo era uma espécie endêmica de Minas Gerais (Brade 1951, Verola 2002, Smidt 2007) e, portanto, é aqui primeiramente registrada no Parque Nacional da Chapada dos Veadeiros, Estado de Goiás. Foi coletada em cerrado e campos rupestres, como rupícola, e em matas de galeria como epífita, entre altitudes de 1.435-1.461 metros, com flores e frutos entre junho e dezembro.

Espécie diagnosticada e diferenciada de suas demais congêneres pelo seguinte conjunto de caracteres: labelo conspicuamente papiloso, vináceo; lobo mediano oblongo com papilas adensadas próximo ao ápice e coluna papilosa ventralmente com estelídeos falcados menores que a antera.

$\mathrm{Na}$ área de estudo, B. adiamantinum é vegetativamente semelhante a $B$. epiphytum, do qual se difere pelos pseudobulbos castanho-amarelados levemente arroxeados (vs. verde-amarelados), folhas não sulcadas longitudinalmente ( $v s$. sulcadas), pétalas e sépalas amarelo-esverdeadas (vs. brancas) e labelo vináceo (vs. amarelo).

De acordo com Smidt (2007), B. adiamantinum e $B$. arianeae Fraga \& E.C. Smidt, duas espécies não relacionadas, são as únicas que possuem coluna papilosa em sua porção ventral. Entretanto, $B$. adimantinum é morfologicamente semelhante a $B$. insectiferum Barb. Rodr., da qual se difere pelas pétalas sésseis ( $v s$. não sésseis), pelo ápice do labelo sub-revoluto ( $v s$. não revoluto) e pelos estelídeos falcados ( $v s$. eretos).

2. Bulbophyllum ciluliae Bianch. \& Bat., Sitientibus Sér. Ci. Biol. 4: 20. 2004.

Figuras 3, $8 \mathrm{f}-\mathrm{h}$

Erva epífita. Rizoma 0,3-0,5 cm compr., entre os pseudobulbos. Pseudobulbos 0,4-0,8 × 0,4-1,2 cm, subglobosos, ápice simétrico, castanho-esverdeados, levemente arroxeados. Folha 0,8-1,8 $\times 0,5-0,9 \mathrm{~cm}$, plana, ereta, oval-elíptica ou elíptica, subcoriácea, ápice agudo, verde-oliva. Racemo 4,1-6,6 cm compr., com 8-10 flores, curvo, laxo; pedúnculo 2,7-4,5 cm compr., raque 1-2,1 cm compr., pêndula. Brácteas, triangulares, membranáceas, ápice agudo; as do pedúnculo 4-7 × 5-10 mm; as florais $0,1-0,3 \times 0,6-1,3 \mathrm{~cm}$, verde-vináceas. Flores 4-6 mm compr., espiraladas na raque, jugo presente, triangular, inconspícuo; ovário + pedicelo 1-2 × 0,7-1 mm, obcônico, verdearroxeado. Sépalas 3-nervadas, membranáceas, glabras, ápice curto acuminado, margem ligeiramente serrulada, vináceas com máculas e estrias esverdeadas; a dorsal 3,1-4 × 1,4-2 mm, largamente oblongoelíptica; as laterais 3,1-4 × 1,8-2,5 mm, largamente ovais, unidas na base formando um mento. Pétalas 2-2,1 $\times 0,4-0,5 \mathrm{~mm}$, lanceoladas, sésseis, 1 -nervadas, membranáceas, base truncada, ápice agudo, margem irregularmente denteada, verde-vináceas. Labelo 2-2,1 × 5-6 mm, 3-lobado, carnoso na região mediana, papiloso, castanho-amarelado, disco com um sulco liso e plano longitudinalmente, hipoquílo e epiquílo diferenciados; lobos laterais, inconspícuos, dentiformes, castanhos; lobo mediano, oval-oblongo, castanho-amarelado, ápice arredondado. Coluna ca. $2 \mathrm{~mm}$ compr., sem papilas, verde-vinácea; estelídeos presentes, 0,9-1 × 0,3-0,4 mm, eretos, petaloides, subfalcados, maiores que a antera, ápice bibraquiado, alvo-esverdeados; dentes presentes, subfalcados, inconspícuos. Pé da coluna ca. $2 \mathrm{~mm}$ compr. Antera ca. $1 \times 1 \mathrm{~mm}$, oval, papilosa, cristada, ápice arredondado, amarelo-alva. Polínias ca. $1 \mathrm{~mm}$ compr., 4, dimórficas, sobrepostas, amarelas. Cápsulas 4,9-5 × 5-5,2 mm, elipsoides, não pendentes, castanhoesverdeadas.

Material examinado: BRASIL. GoIÁs: Cavalcante, Parque Nacional da Chapada dos Veadeiros, Rio Preto das Sete Quedas, próximo à mata de galeria, $14^{\circ} 05^{\prime} 54,7^{\prime \prime} \mathrm{S}, 4^{\circ} 45^{\prime} 01^{\prime \prime} \mathrm{W}, 1066 \mathrm{~m}, 25-\mathrm{V}-2018$, fl., fr., I.S. Santos et al. 474 (UFG).

Material examinado adicional: BRASIL. DisTRITo FEDERAL: Planaltina, em mata de encosta, 15-XI-2013, fl., J.H. Lima 59 (UB); Setor de Mansões do Lago Norte, beirando o córrego Taquari, 12-II-1990, fl., fr., L.B. Bianchetti 848 (CEN); Sobradinho, DF-205, $2 \mathrm{~km}$ após a entrada para a Comunidade Córrego do Ouro, 7-II-2001, fl., A.A. Santos et al. 880 (CEN); Gorás: Abadiânia, margem direita do rio Antas, 16²19'23"S, 48³0'06"O, 830 m, 8-VI-2005, fr., G.P. Silva et al. 10131 (CEN); Cristalina, RPPN Linda Serra dos Topázios, na região de junção entre o rio Areião e o rio Topázio, 15-III-1998, fl., L.B. Bianchetti \& R.S. Oliveira s.n. (CEN49644); Ipameri, Fazenda Santo Antônio do Fundão, córrego afluente, margem 


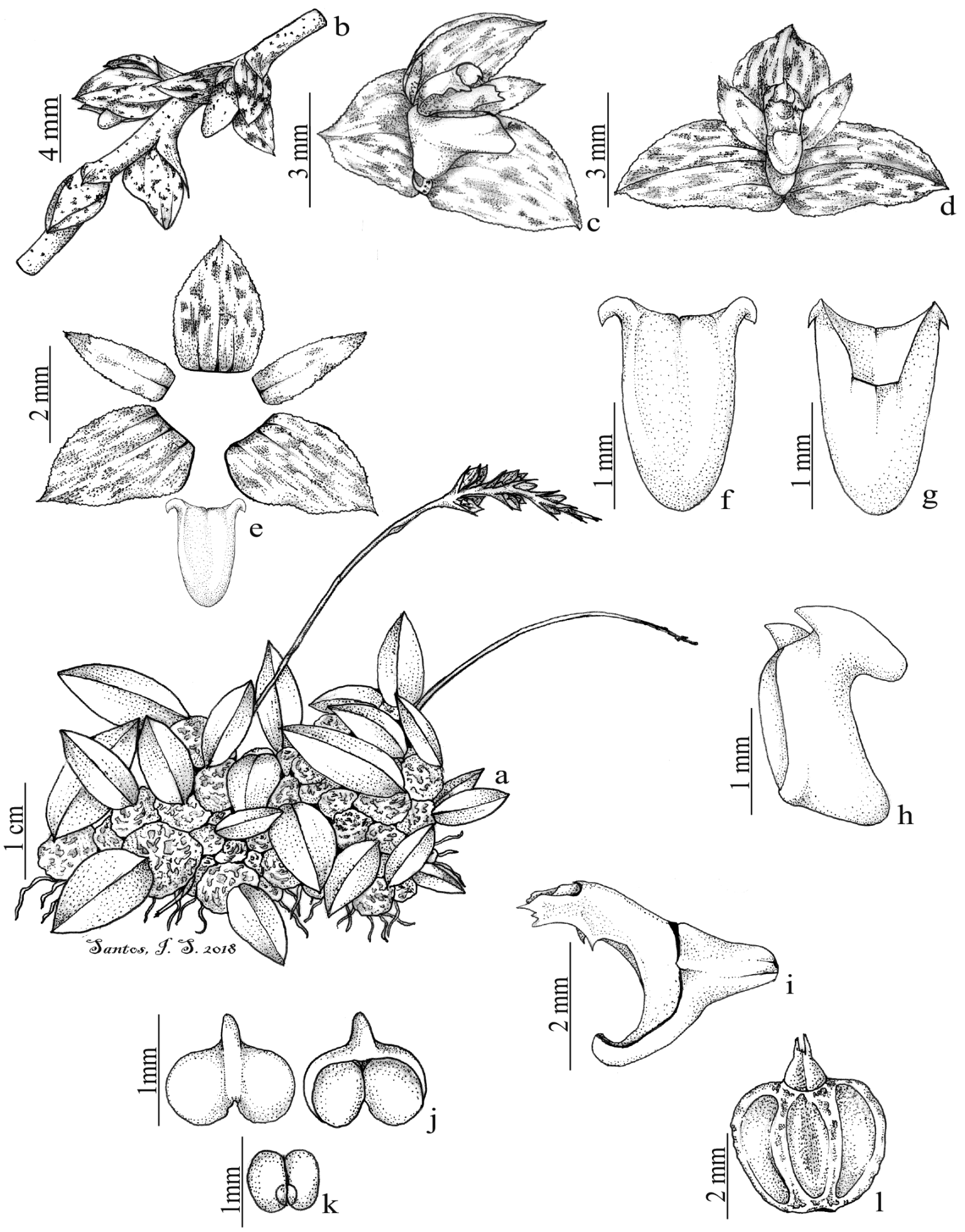

Figura 3. Bulbophyllum ciluliae Bianch. \& Bat. a. Hábito. b. Detalhe da inflorescência. c. Flor em vista lateral. d. Flor em vista frontal. e. peças florais dissecadas. f. Labelo em vista frontal. g. Labelo em vista dorsal. h. Labelo em vista lateral. i. Coluna. j. Antera em vista dorsal e ventral. k. Polínias. 1. Cápsula. (I.S. Santos et al. 474).

Figure 3. Bulbophyllum ciluliae Bianch. \& Bat. a. Habit. b. Detail of inflorescence. c. Flower, side view. d. Flower, frontal view. e. Floral pieces dissected. f. Lip, frontal view. g. Lip, dorsal view. h. Lip, side view. i. Column. j. Anther, dorsal and lateral view. k. Pollinia. 1. Capsule. (I.S. Santos et al. 474). 
esquerda do rio Corumbá, área de desmatamento, em mata ripária, $17^{\circ} 43^{\prime} 00^{\prime \prime} \mathrm{S}, 48^{\circ} 10^{\prime} 00^{\prime \prime} \mathrm{O}, 830 \mathrm{~m}$, 23-III-1995, fl., T.B. Cavalcanti et al. 1390 (AMES, CEN, HUEFS, SP).

Bulbophyllum ciluliae é uma espécie endêmica do Brasil (BA, DF e GO) onde cresce como rupícola, em afloramentos de rochas, ou epífita em matas de galeria (Bianchetti \& Batista 2004, Smidt 2007). Neste estudo foi encontrada apenas como epífita em mata de galeria no município de Cavalcante com flores e frutos entre fevereiro e março. Pode ser reconhecida pelos racemos com flores espiraladas de pétalas verde-vináceas com margem irregularmente denteada e sépalas com margem serrulada, além de possuir a antera cristada e estelídios petaloides e maiores que a última (Bianchetti \& Batista 2004, Smidt 2007). Quando estéril, assemelha-se a B. plumosum pelo formato das folhas e pseudobulbos. Porém, $B$. plumosum apresenta pseudobulbos ovoide-globosos (vs. subglobosos), flores alternas na raque, pétalas e sépalas de margem ciliada ( $v s$. espiraladas; margem não ciliada); labelo rosa-alvo com máculas e estrias vináceas ( $v s$. castanho-amarelado), lobos laterais auriculares (vs. dentiformes) e estelídios filiformes menores que as anteras (vs. petaloides maiores que as anteras).

3. Bulbophyllum epiphytum Barb. Rodr., Gen. Sp. Orchid. 1:40. 1877.

Figuras 4, 9a-b

Erva epífita ou rupícola. Rizoma 0,2-0,7 cm compr., entre os pseudobulbos. Pseudobulbo 0,3-1,6 × 0,3-1,2 cm, piriforme, ápice simétrico, verde-amarelado. Folha 1,1-6,8 × 0,2-0,4 cm, cilíndrica, ereta ou pouco curvada, carnosa, sulcada longitudinalmente, ápice agudo, verde-oliva. Racemo 6-12 cm compr., com 16-47 flores, pouco curvado, congesto; pedúnculo 2-4,3 cm compr., raque 4-8 cm compr., pêndula. Brácteas triangulares, membranáceas, ápice agudo; as do pedúnculo $0,1-0,6 \times 0,2-0,3 \mathrm{~cm}$; as florais $0,1-0,4 \times 0,05-0,2$ $\mathrm{cm}$, creme. Flores 4,9-7,1 mm compr., espiraladas na raque, jugo ausente; ovário + pedicelo 0,9-1,2 × 0,9-1 $\mathrm{mm}$, obcônico, verde-claro. Sépalas 1-nervadas, membranáceas, glabras, ápice agudo, margem inteira, brancas; a dorsal 3,9-4 × 1-1,2 mm, lanceolada; as laterais 4-5,9 × 1,4-1,5 mm, oval-lanceoladas, falcadas, unidas na base formando um mento. Pétalas 2,7-4,0 × 0,8-1,1 mm, lanceoladas, sésseis, 1-nervadas, membranáceas, base truncada, ápice agudo, margem inteira ou ligeiramente papilosa próximo ao ápice, brancas. Labelo 0,3-0,4 × 1,1-1,2 cm, 3-lobado, carnoso, amarelo, papilas ausentes ou presentes da base até a região mediana, disco sulcado longitudinalmente, hipoquílo e epiquílo pouco diferenciados; lobos laterais inconspícuos, dentiformes, falcados; lobo mediano elíptico-oboval, margem serrilhada, ápice arredondado. Coluna 1-1,1 mm compr., sem papilas, verde-alva; estelídeos presentes, ca. 0,2-0,3 mm compr., dentiformes, menores que a antera, ápice agudo, esbranquiçados; dentes ausentes. Pé da coluna 0,6-0,8 mm compr. Antera, 0,4-0,7 × 0,5-0,7 mm, oval, glabra, ápice arredondado, amarelo-alva. Polínias ca. 0,4-0,6 mm compr., 4, dimórficas, sobrepostas, amarelas. Cápsulas 4-6 × 4-5 mm, elipsoides, não pendentes, verde-amareladas.

Material examinado: BRASIL. Gorás: Alto Paraíso de Goiás, Parque Nacional da Chapada dos Veadeiros,16-II-2017, fl., I.S. Santos et al. 299 (UFG); idem, próximo ao bueiro, ca. de $500 \mathrm{~m}$, próximo ao Morro do Japonês, 27-I-2018, fl., I.S. Santos et al. 375 (UFG).

Material examinado adicional: Brasil. BAHIA: Cascavel, s.d., E.C. Smidt 737 (HUEFS); Goiás: Chapada dos Veadeiros, ca. 3740 km N. Alto Paraíso, na GO-118, em direção a Teresina de Goiás, na altura

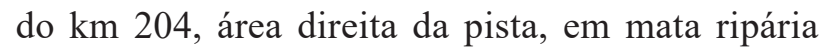
inundável, 11-X-1999, fl., J.A.N. Batista 950 (CEN); Mossâmedes, Serra Dourada, ca 20 km S. E. de Goiás Velho, $14^{\circ} \mathrm{S}, 50^{\circ} \mathrm{W}, 800$ m, 19-I-1966, fl., H.S. Irwin, R. Souza \& R.R. Santos 11759 (F, IAN, K, MO, NY, UB, US); near Goiás, on sandstone outcrop on sumit of Serra, 18-XII-1968, fl., R.M. Harley \& G.M. Barroso et al. $11321(\mathrm{~K})$; Pirenopólis, Serra dos Pireneus, ca. 20 km E. of Pirenópolis, 1000 m; 16-I-1972, fl., H.S. Irwin et al. 34322 (MO, NY, UB, UEC); J. Semir et al. 20593 (RB); idem, sobre pedras, em fendas de rochas, 1350 m, 9-XII-1987, fl., J. Semir et al. 20603 (RB); Alto da Samambaia, sobre pedras, 21-I-1966, fl., E.P. Heringer 10948 (IAN, UB); MINAS GERAIS: Cachoeira da Fumaça, próximo ao riacho, 11-XI-1998, fl., A.O. Simões et al. 457 (UEC); São João del Rei, estrada de Morro do Ferro para Passa Quatro, 8 km de Morro do Ferro, sentido Passa Quatro, Serra das Vertentes, $21^{\circ} 13^{\prime} 00^{\prime \prime S}, 44^{\circ} 54^{\prime} 00^{\prime \prime} \mathrm{W}, 800$ m, 26-II-2000, fr., T.B. Cavalcanti et al. 2563 (CEN); MATO GROSSO DO SUL: Amambaí, Rod. MT - 62, Rio Amambaí, 14-XII-1983, fl., G. Hatschbach 47226 (HUEFS); Paraná: Tuneiras do Oeste, Reserva Biológica das Perobas,

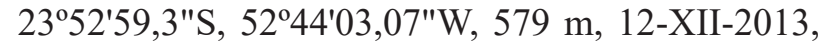



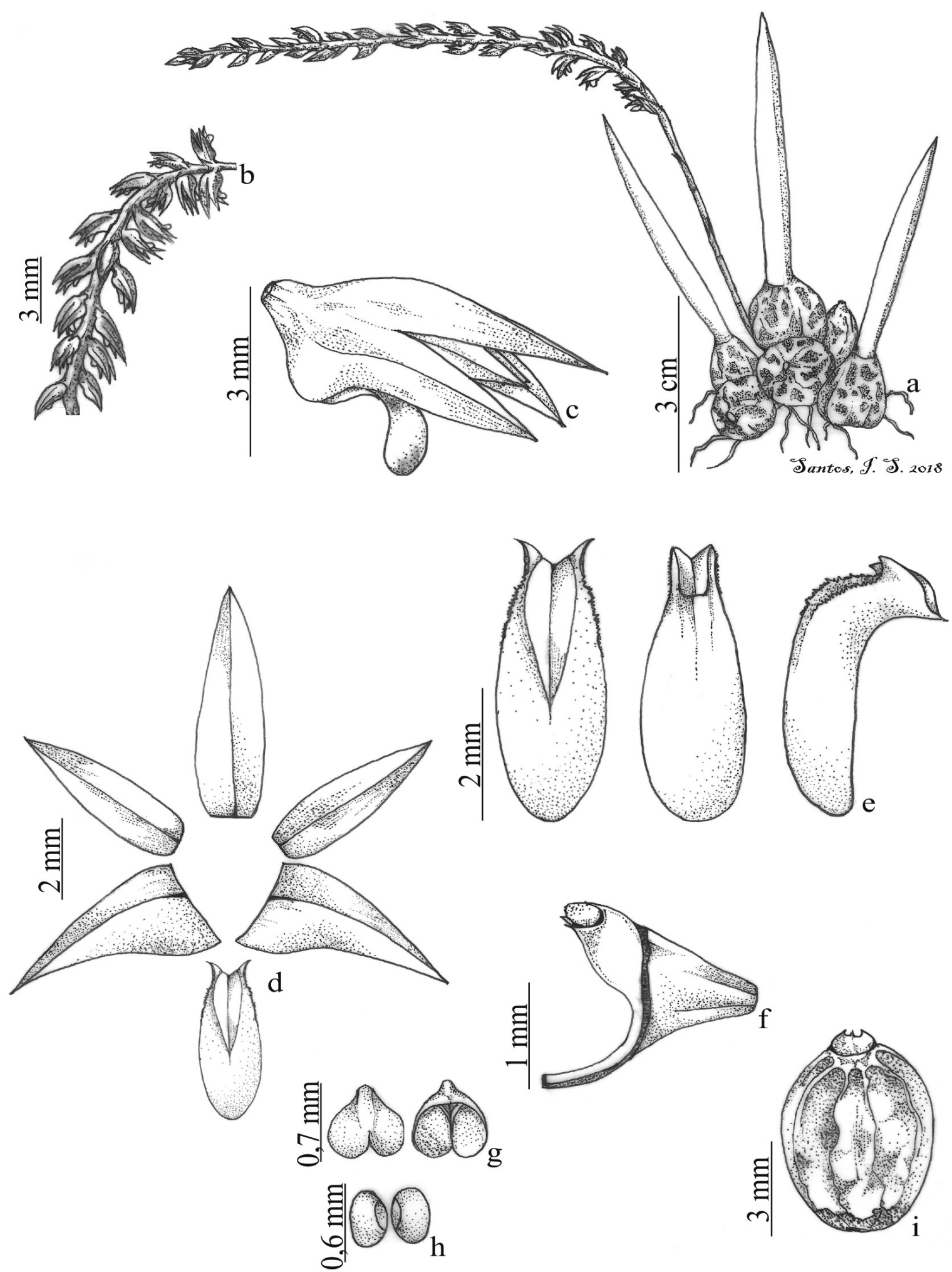

Figura 4. Bulbophyllum epiphytum Barb. Rodr. a. Hábito. b. Detalhe da inflorescência. c. Flor em vista lateral. d. Peças florais dissecadas. e. Labelo em vista frontal, dorsal e lateral. f. Coluna. g. Antera em vista dorsal e ventral. h. Polínias. i. Cápsula (I.S. Santos et al. 375).

Figure 4. Bulbophyllum epiphytum Barb. Rodr. a. Habit. b. Detail of inflorescence. c. Flower, lateral view. d. Floral pieces dissected. e. Lip, frontal, dorsal and side view. f. Column. g. Anther, dorsal and ventral view. h. Pollinia. i. Capsule (I.S. Santos et al. 375). 
fl., H.R. Barbosa \& Barbosa et al. s.n. (HCF123262); SÃo PAulo: Cidade Jardim, 5-X-1930, fl., A. Gehrt 29439 (NY).

Bulbophyllum epiphytum ocorre no Brasil e na Bolívia (Smidt 2007), sendo no primeiro conforme o BFG (2015) encontrada nas regiões Nordeste (BA), Centro-Oeste (GO, MS), Sudeste (ES, MG, SP) e Sul (PR), crescendo em afloramentos rochosos e em matas de galeria, sobre rochas e árvores, respectivamente (Smidt 2007). No PNCV esta espécie parece rara, pois foi encontrada apenas no município de Alto Paraíso de Goiás em mata de galeria como epífita. Floresce e frutifica entre novembro e fevereiro.

Assemelha-se morfologicamente a B. rupicolum, da qual se diferencia pelas folhas eretas ou pouco curvadas ( $v s$. curvadas), pseudobulbo piriforme ( $v s$. globoso), pétalas com nervura central não vinácea e margem ligeiramente papilosa próximo ao ápice ( $v s$. com nervura vinácea e margem sem papilas), labelo mais largo em sua porção distal do que basal (vs. mais largo na base do que em sua porção distal), com 3-4 × 1,1-1,2 mm (vs. $2 \times 0,7-1 \mathrm{~mm})$, e margem do lobo mediano do labelo serrilhada ( $v s$. não serrilhada). Assim como foi reportado por Verola (2002), B. epiphytum apresenta flores aromáticas, com um odor cítrico característico.

4. Bulbophyllum exaltatum Lindl., Ann. Mag. Nat. Hist. 10: 186. 1842.

Figuras 5, 9c-g

Erva rupícola. Rizoma 1,2-3 cm compr., entre os pseudobulbos. Pseudobulbo 1,5-4,5 × 0,9-3,2 cm, ovoide-oblongo, ápice assimétrico, verde-limão. Folha 1-7,5 × 0,7-4,5 cm, oblongo-elíptica, plana, ereta, carnosa, ápice agudo, verde-amarelada. Racemo 12,5-72 cm compr., com 13-35 flores, ereto, laxo; pedúnculo 5-48 cm compr., raque 7-26 cm compr, ereta. Brácteas, triangulares, membranáceas, ápice, agudo; as do pedúnculo $0,9-17 \times 0,2-0,6 \mathrm{~cm}$; as florais $0,1-1,2 \times 0,1-0,5 \mathrm{~cm}$, creme. Flores $11-13 \mathrm{~mm}$ compr., espiraladas na raque, jugo presente, triangular, conspícuo; ovário + pedicelo 0,4-3 × 0,7-1 mm, obcônico, verde. Sépalas 3-nervadas, carnosas, glabras, ápice agudo, margem inteira, brancas com máculas vináceas; a dorsal 7-10,1 × 3-4 mm, oval-lanceolada; as laterais 7-1 × 3,8-5 mm, ovallanceoladas, falcadas, unidas na base formando um mento. Pétalas 3-5 × 1,5-2,3 mm, oval-lanceoladas, sésseis, 1-nervadas, membranáceas, base truncada, ápice agudo, margem curtamente ciliada, brancas com máculas vináceas. Labelo 4,8-7 × 2-3,6 mm, 3-lobado, carnoso, vináceo, conspicuamente papiloso; calo presente, elipsoide, vináceo, hipoquílo e epiquílo diferenciados; lobos laterais conspícuos, 1-2 × 1-2 mm, eretos, auriculares, brancos com máculas vináceas, margem curtamente ciliada, vinácea; lobo mediano 5,0-7,0 × 2-4 mm, oboval, papiloso, vináceo, ápice arredondado, branco. Coluna 1,8-2 × 2-2,5 mm, sem papilas, verde-alva com pontoações vináceas ventralmente; estelídeos presentes, ca. 0,3-0,4 mm compr., filiformes, maiores que a antera, ápice agudo, esbranquiçados com pontoações vináceas; dentes presentes, conspícuos. Pé da coluna 0,8-1 mm compr. Antera, 0,6-1 × 0,5-0,7 mm, oval, glabra, ápice arredondado, alvo-esverdeada. Polínias ca. 1 mm compr., 4, dimórficas, enfileiradas, amarelas. Cápsulas 0,8-2,6×0,4-1,5 cm, obovoides, pendentes, verde-amareladas, levemente arroxeadas.

Material examinado: BRASIL. GoIÁs: Alto Paraíso de Goiás, Parque Nacional da Chapada dos Veadeiros, 21-IX-2017, fr., I.S. Santos et al.222 (UFG); idem, $14^{\circ} 01^{\prime} 54^{\prime \prime S}, 47^{\circ} 31^{\prime} 50^{\prime \prime W}, 1446$ m, 22-IX-2017, fr., I.S. Santos et al. 240 (UFG); idem, 15-XII-2017, fl., I.S. Santos et al. 287 (UFG); idem, ca. de $350 \mathrm{~m}$ da casa abandonada, Cruzeiro, 135' $44^{\prime \prime S}, 47^{\circ} 29^{\prime} 48^{\prime \prime} \mathrm{W}$, 1480 m, 24-II-2018, fl., I.S. Santos et al. 426 (UFG); idem, 28-IV-2018, fl., fr., I.S. Santos et al. 468 (UFG).

Material examinado adicional: BRASIL. BAHIA: Jacobina, Piemonte da Diamantina, Serra do Tombador, acesso pela fazenda Lajedinho, $11^{\circ} 15^{\prime} 16^{\prime \prime S}$, 40²2'09"W, 911 m, 28-IV-2012, fl., T.L. Vieira, A. Stadnik \& L.M. Moura 95 (ALCB); Morro do Chapéu, Piemonte da Diamantina, próximo à estrada para o Morrão, 6-VII-2009, fl., A.S.F. Castro 2177 (EAC); Morrão, 1500 m, 16-VII-1979, fl., G. Hatschbach \& O. Guimarães 42392 (CEPEC); Goiás: Alto Paraíso de Goiás, $14^{\circ} 01^{\prime} 52^{\prime \prime S}, 47^{\circ} 30^{\prime} 45^{\prime \prime W}, 3-V I I-1978$, fr., S.B. Silva \& J. Oliveira 51 (RB); Rodovia GO-16, $10 \mathrm{~km}$ ao norte de Alto Paraíso, em campo rupestre, 10-II-1994, fl., G. Hatschbach, M., M. Hatschbach \& J.M. Silva 60302 (HUEFS, RB); Chapada dos Veadeiros, 8-IX-1996, fr., H. S. Irwin et al. 12354 (UB); idem, fl., fr., H.S. Irwin et al. 12644 (F, IAN, $\mathrm{NY}, \mathrm{RB}, \mathrm{UB}, \mathrm{US})$; idem, Cruk and adjacent rocky slopes, ca. $15 \mathrm{~km}$. W of Veadeiros, $14^{\circ} \mathrm{S}, 47^{\circ} \mathrm{W}$, 1000 m, 12-II-1996, fl., H.S. Irwin et al. 12664 (NY); idem, Chapada dos Veadeiros. Cerrado on outcrops with surrounding wet campos (brejos) and adjacent gallery florest, ca $25 \mathrm{~km} \mathrm{~N}$. of Alto Paraíso, $1250 \mathrm{~m}$, 23-III-1971, fl., H. S. Irwin, R.M. Harley \& G.L. Smith 


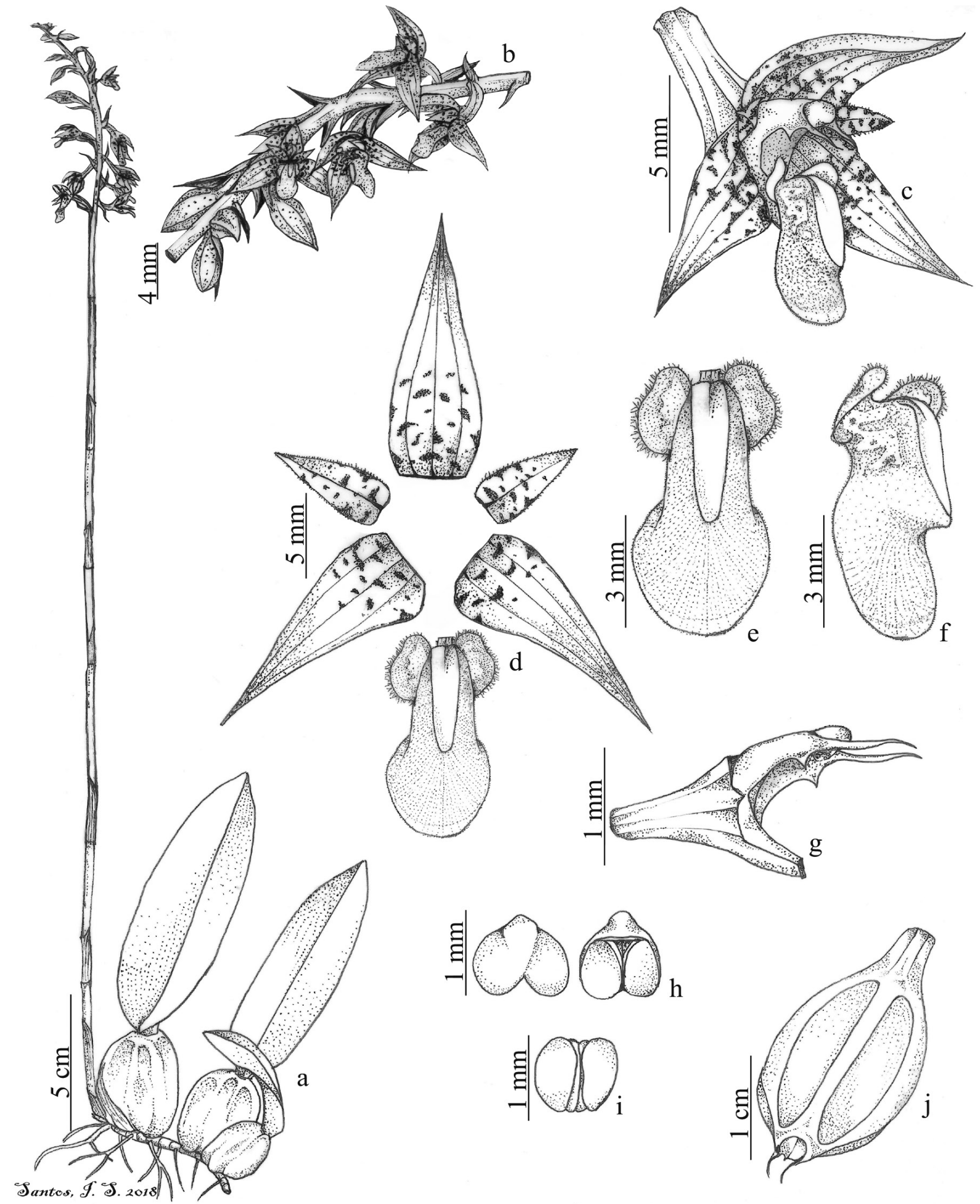

Figura 5. Bulbophyllum exaltatum Lindl. a. Hábito. b. Detalhe da inflorescência. c. Flor. d. Peças florais dissecadas. e. Labelo em vista frontal. f. Labelo em vista lateral. g. Coluna. h. Antera em vista e ventral. i. Polínias. j. Cápsula. (I.S. Santos et al. 426).

Figure 5. Bulbophyllum exaltatum Lindl. a. Habit. b. Detail of inflorescence. c. Flower. d. Floral pieces dissected. e. Lip, frontal view. f. Lip, side view. g. Column. h. Anther, dorsal and ventral view. i. Pollinia. j. Capsule. (I.S. Santos et al. 426). 
33025 (UB); 7 km depois de Alto Paraíso, em campo rupestre em fendas de pedras 18-III-1976, fr., J. Semir s.n. (UEC70739); Corumbaíba, em área alagada, $17^{\circ} 50^{\prime} 75^{\prime \prime S}, 48^{\circ} 27^{\prime} 13^{\prime \prime W}, 595$ m, 28-VIII-1997, fr., H.G.P. Santos et al. 505 (CEN); Caldas Novas, bacia de inundação do AHE Corumbá, em copa de árvores semi-inundadas, 2-X-1996, fr., T.B. Cavalcanti et al. 2088 (CEN); Minas GeraIs: Caldas, 18-VII-1968, fl., S.E. Henschen 919 (US); Conceição do Mato Dentro, Parque Natural Municipal do Ribeirão do Campo, 23-IV-2003, fl., R.C. Mota et al. 2563 (BHCB); caminho para Cachoeira do Tabuleiro, $19^{\circ} 05^{\prime} 10^{\prime \prime} \mathrm{S}$, 433'ㅇ" W, 1146 m, II-2005, fl., P.L. Ribeiro 175 (HUEFS); Joaquim Felício, Serra do Cabral,1"S,

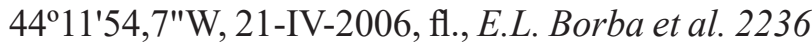
(BHCB); Roraima: Paracaima, s.d. fl., E.C. Smidt 341 (HUEFS); São Paulo: Atibaia, Pedra Grande, 21-V-1997, fl., fr., E.L. Borba 301 (UEC); Jundiaí, Serra do Japi, Sentido Bairro Eloy Chaves, próximo à represa do DAE, 21-II-1999, fl., E.R. Pansarin 403 (HUEFS).

Bulbophyllum exaltatum se distribui amplamente na América do Sul, sendo no Brasil conforme o BFG (2015) registrada para os seguintes estados: AM, BA, ES, GO, MG, RJ, RO, SP, SC. Na área de estudo, foi coletada apenas na região do Cruzerio (Serra do Pouso Alto) no município de Alto Paraíso de Goiás crescendo em cerrado rupestre sobre rochas com flores e frutos entre dezembro e abril.

Esta espécie não é confundida com nenhuma das congêneres estudadas por apresentar caracteres vegetativos e reprodutivos que lhes são peculiares (eg., rizoma longo, 1,2-3 cm compr., labelo vináceo com máculas brancas, polínias enfileiradas). Adicionalmente, pode ser reconhecida pelas folhas oblongo-elípticas, flores verde-esbranquiçadas com máculas vináceas, o labelo com lobos laterais orbiculares.

Entretanto, B. exaltatum faz parte do "complexo B. exaltatum Lindl.", que engloba espécies morfologicamente semelhantes e de difícil delimitação (ca. 15 táxons), pertencentes a $B$. sect. Didactyle. Esse complexo compreende plantas rupícolas que ocorrem nas regiões Norte, Nordeste e Sudeste do Brasil, em áreas de altitude, sendo que os principais caracteres que permitem a distinção dentre os táxons se resume à morfologia floral, sobretudo ao labelo (Ribeiro 2006).

5. Bulbophyllum plumosum (Barb. Rodr.) in Mart., Fl. Bras. 3(5): 614. 1902.

Figuras 6, 9h-i
Erva epífita e rupícola. Rizoma 0,1-0,6 cm compr., entre os pseudobulbos. Pseudobulbo 0,4-1,6 $\times$ 0,3-2 cm, ovoide-globoso, ápice simétrico, verde-limão. Folha 1,2-4,3 ×0,5-1,1 cm, plana, elíptica ou oval-lanceolada, ereta, cartácea, ápice agudo, verde-oliva. Racemo 4,5-14 cm compr., com 3-10 flores, pouco curvado, laxo; pedúnculo 4-7 cm compr., raque 2-9,3 cm compr., pêndula ou ereta. Brácteas, triangulares, paleáceas, ápice, agudo; as do pedúnculo $0,3-7 \times 0,2-0,6 \mathrm{~cm}$; as florais $0,3-0,9 \times 0,2-0,3 \mathrm{~cm}$, esverdeadas. Flores $14-23 \mathrm{~mm}$ compr., alternas na raque, jugo presente, triangular, conspícuo; ovário + pedicelo 1-3 × 0,4-0,6 mm, obcônico, verde. Sépalas 3-nervadas, membranáceas, ápice agudo, margem longamente ciliada, verde-róseas, tricomas amarelo-arroxeados; a dorsal 14-20 × 1,8-3 mm, lanceolada; as laterais 14-20 × 1,9-3 mm, triangularlanceoladas, unidas por quase toda a sua extensão. Pétalas 4,5-5,3 × 1,5-2 mm, lanceoladas, sésseis, 1-nervadas, membranáceas, base truncada, ápice agudo, margem ciliada, brancas com máculas vináceas. Labelo 10-13,2 × 2-2,4 mm, 3-lobado, carnoso, rosa-alvo com máculas e estrias vináceas, papiloso, hipoquílo e epiquílo diferenciados, região entre o hipoquílo e mesoquílo carnosa e longamente ciliada; disco sulcado longitudinalmente; calo presente, elipsoide; lobos laterais 1,8-4 × 1,3-2 mm, auriculares, margem longamente ciliada, brancos com máculas vináceas; lobo mediano 7-10 × 1-2,1 mm, espatulado, rosa-alvo com máculas e estrias vináceas, 3-nervado, ápice arredondado. Coluna 2-3,1 × 1,9-2 mm, sem papilas, branca, com pontoações vináceas; estelídeos presentes, ca. 0,4 $\mathrm{mm}$ compr., filiformes, menores que a antera, ápice agudo, esbranquiçados; dentes presentes, subfalcados, conspícuos. Pé da coluna ca. $1 \mathrm{~mm}$ compr. Antera, 0,4-0,7 × 0,5-0,6 mm, oval, papilosa, ápice arredondado, alvo-esverdeada. Polínias ca. 0,4-0,6 mm comp., 4, dimórficas, sobrepostas, amarelas. Cápsulas 1,5-1,7 × 0,6-0,7 cm, obovoides, não pendentes, verde-amareladas.

Material examinado: BRASIL. GoIÁs: Alto Paraíso de Goiás, Parque Nacional da Chapada dos Veadeiros, Cruzeiro, em mata de galeria, 15-XII-2017, fl., fr., I.S. Santos et al. 298 (UFG).

Material examinado adicional: BRASIL. BAHIA: Abaíra, Jambreiro, $13^{\circ} 17^{\prime} \mathrm{S}, 4^{\circ} 52^{\prime} \mathrm{W}, 1100-1180 \mathrm{~m}$, 31-III-1994, fl., W. Ganev 3003 (HUEFS); Distrito Federal: Alexânia, Fazenda Cafundó, margem esquerda do rio Corumbá, $16^{\circ} 08^{\prime} 25^{\prime \prime} \mathrm{S}, 48^{\circ} 34^{\prime} 41^{\prime \prime} \mathrm{O}, 830$ m, 9-V-2007, fl., G.P. Silva et al. 7655 (CEN); Parque 


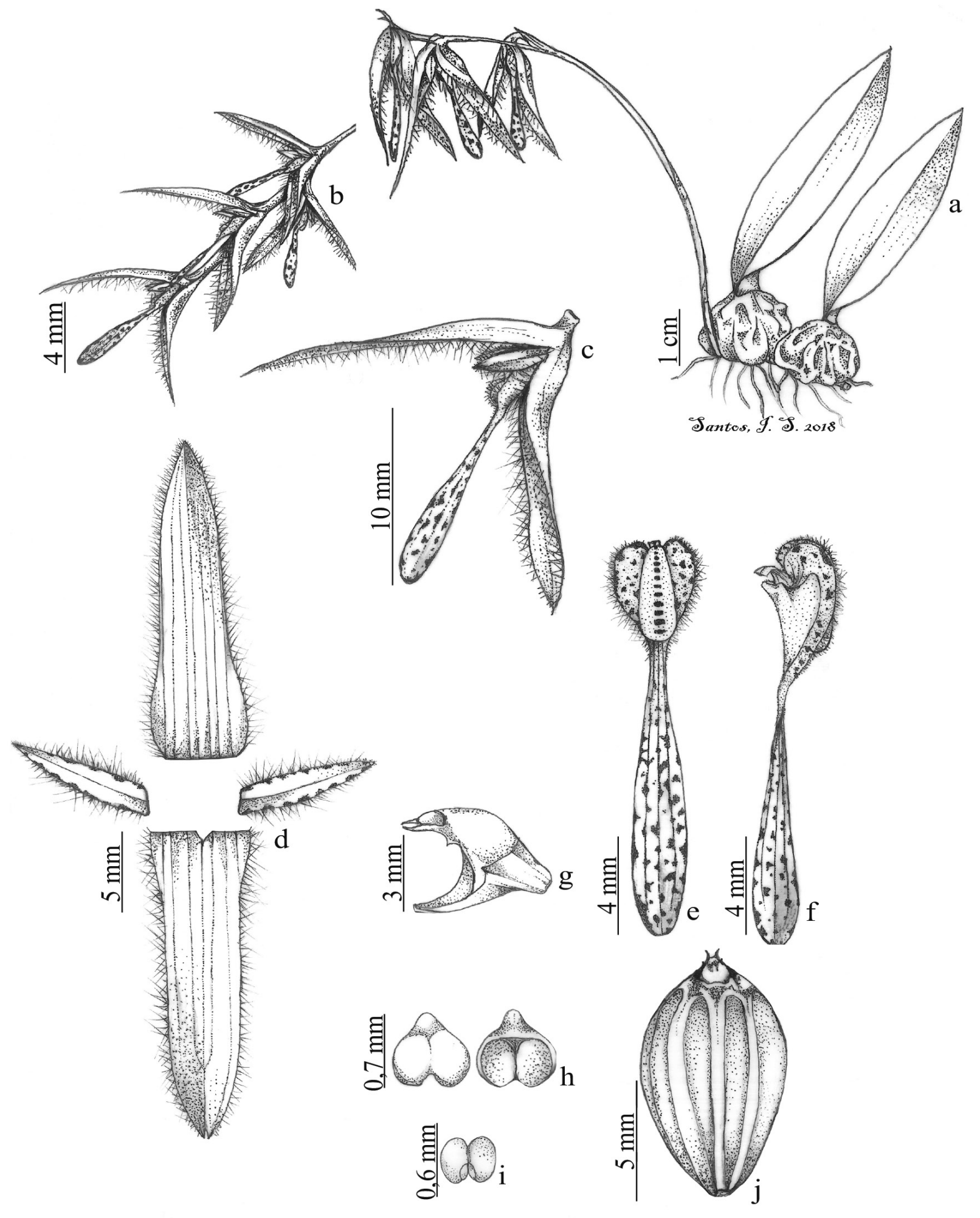

Figura 6. Bulbophyllum plumosum (Barb. Rodr.) Cogn. a. Hábito. b. Detalhe da inflorescência. c. Flor em vista lateral. d. Peças florais dissecadas. e. Labelo em vista frontal. f. Labelo em vista lateral. g. Coluna. h. Antera em vista dorsal e ventral. i. Polínias. j. Cápsula. (I.S. Santos et al. 298).

Figure 6. Bulbophyllum plumosum (Barb. Rodr.) Cogn. a. Habit. b. Detail of inflorescence. c. Flower, side view. d. Floral pieces dissected. e. Lip, frontal view. f. Lip, side view. g. Column. h. Anther, dorsal and ventral view. i. Pollinia. j. Capsule. (I.S. Santos et al. 298). 
Nacional de Brasília, em mata de galeria, 19-X-1998, fl., A.A. Santos 312 (CEN); Setor das Mansões do Lago Norte, Chácara de propriedade da Sra. Cilúlia M. Maury, próximo do Trecho Oito, beirando o Córrego Taguarí, em mata semi-decídua de encosta; 12-II1990, fl., L. Bianchetti \& J.A.N. Batista 847 (CEN); Taguatinga, Floresta Nacional de Brasília (Área I), em mata de galeria, $15^{\circ} 79^{\prime} 01^{\prime \prime} \mathrm{S}, 48^{\circ} 06^{\prime} 76^{\prime \prime} \mathrm{W}, 1200$ m, 15-IX-2012, J.H. Lima 24 (UB); Minas Gerais: Caldas, Pedra Branca, s.d., fl., C.N. Fraga 4059 (RB); Carrancas, Cachoeira da Zilda, 27-IV-1999, fl., A.O. Simões, A.W. Jannini \& R.B. Singer 779 (UEC); Vargem Grande, em afloramento, 11-XI1998, fl., A.O. Simões et al. 442 (UEC); Rio Pardo de Minas, Distrito de Serra Nova, Parque Estadual da Serra Nova, Cadeia do Espinhaço, $15^{\circ} 36^{\prime} 55,7^{\prime \prime S}$, 42 44'09,0"W, 810 m, 12-III-2007, fl., A. Salino et al. 11719 (BHCB); Paraná: Castro, Carambeí, Rio São João, 14-IV-1966, fl., G. Hatschbach 14206 (MBM); Ponta Grossa, arredores do Buraco do Padre, $25^{\circ} 10^{\prime} 19^{\prime \prime S}, 49^{\circ} 58^{\prime} 04,1$ "W, 946 m, 21-V-2011, fl., G.L. Oliveira et al. s.n. (HCF9493); Porto Amazonas, 01041916, fl., P.K.H. Dusen 18060 (P); idem, Villa Velha, 26-II-1910, fl., P.K.H. Dusén 9483 (F, NY).

Espécie endêmica do Brasil, registrada para as regiões Nordeste (BA), Centro-Oeste (DF, GO), Sudeste (ES, MG, SP) e Sul (PR, RS), onde cresce nos cerrado e campos rupestres, na Mata Atlântica e no semiárido, em afloramentos de rochosos ou matas de galeria, como rupícola ou epífita, respectivamente (BFG 2015). Na área estudada foi encontrada apenas como epífita, em mata de galeria, e observada como rupícola em cerrado rupestre, no município de Alto Paraíso de Goiás, com flores e frutos entre fevereiro e abril.

Entre as demais espécies estudadas Bulbophyllum plumosum é mais semelhante, quando estéril, a $B$. ciluliae pelo porte diminuto e pelas folhas elípticas. No entanto em B. ciluliae os pseudobulbos são subglobosos ( $v s$. ovoide-globosos), as flores têm pétalas verde-vináceas com margem irregularmente denteada (vs. brancas com máculas vináceas, ciliadas), sépalas unidas apenas na base ( $v s$. unidas por toda a sua extensão), vináceas com máculas e estrias esverdeadas e margem ligeiramente erosa, antera cristada (vs. verde-róseas, margem ciliada e antera não cristada); labelo sem calo (vs. com calo), estelídios petaloides maiores que as anteras ( $v s$. filiformes, menores que as anteras), lobos laterais do labelo dentiformes ( $v s$. auriculares) e lobo mediano elíptico (vs. espatulado).

Adicionalmente, B. plumosum é morfologicamente relacionado a B. gehrtii E.C. Smidt \& Borba, uma espécie endêmica da região sudeste $(\mathrm{MG}, \mathrm{SP})$ do
Brasil (Barros et al. 2015), distinguindo-se deste último pelas folhas elípticas ou oval-lanceoladas (vs. lineares), epiquílo do labelo plano (vs. côncavo) e margens do hipoquílo pilosas (vs. pilosas entre o hipoquílo e o epiquílo).

6. Bulbophyllum rupicolum Barb. Rodr., Gen. Sp. Orch. 1: 39. 1877.

Figuras 7, 9j-1

Erva rupícola e epífita. Rizoma 0,1-1,4 cm compr., entre os pseudobulbos. Pseudobulbo 0,4-2,1 × 0,3-1,4 cm, globoso, ápice simétrico, verdeamarelado. Folha 1,1-5,5 ×0,3-0,6 cm, cilíndrica, curvada, carnosa, sulcada longitudinalmente, ápice agudo, verde-oliva. Racemo 5-11,3 cm compr., com 19-63 flores, curvado, congesto; pedúnculo $3-14,5 \mathrm{~cm}$ compr., raque 1,6-13,2 cm compr., pêndula. Brácteas, oval-triangulares a triangulares, membranáceas, ápice, agudo; as do pedúnculo 0,2-0,7 × 0,1-0,8 cm, as florais 1,2-4 × 0,8-1 mm, creme. Flores 4,3-6,0 $\mathrm{mm}$ compr., espiraladas na raque, jugo ausente; ovário + pedicelo 0,8-1 × 0,7-1 mm, obcônico, verdeclaro. Sépalas 1-nervadas, membranáceas, ápice agudo, glabras, brancas; a dorsal 3,5-4 × 1-1,2 mm, lanceolada; as laterais 3,5-5 × 1-2 mm, ovallanceoladas, falcadas, unidas na base em um mento. Pétalas 1,9-3 × 0,7-1,1 mm, elíptico-lanceoladas, sésseis, 1-nervadas, membranáceas, base truncada, ápice agudo, margem inteira, brancas com nervura central vinácea. Labelo $2 \times 0,7-1 \mathrm{~mm}, 3$-lobado, carnoso, amarelo, região basal paralela à coluna com margem inteira, papilas distribuídas da base até a metade da face superior do labelo, disco sulcado longitudinalmente, hipoquílo e epiquílo pouco diferenciados, lobos laterais dentiformes; lobo mediano oblongo-oboval, margem inteira glabra, ápice arredondado. Coluna 0,2-0,3 × 0,1 cm, sem papilas, verde-alva; estelídeos presentes, ca. 0,2-0,3 mm compr., dentiformes, menores que a antera, ápice agudo, esbranquiçados; dentes ausentes. Pé da coluna 0,8-0,9 mm compr. Antera ca. 0,5-0,6 mm, oval, glabra, ápice arredondado, amarelo-alva. Polínias ca. 0,5 mm compr., 4, dimórficas, sobrepostas, amarelas. Cápsulas 4-6 × 4-5 mm, ovoide-globosas, não pendentes, verde-amareladas.

Material examinado: BRASIL. GoIÁs: Alto Paraíso de Goiás, Parque Nacional da Chapada dos Veadeiros, nas bordas da estrada para o Rio Preto das Sete Quedas, 25-VIII-2017, fr., I.S. Santos, M.J. Silva \& R. G. Matos 183 (UFG); idem, 1401'51"S, 47º31'50"W, 1446 m, 22-IX-2017, fr., I.S. Santos et al. 239 (UFG); idem, 

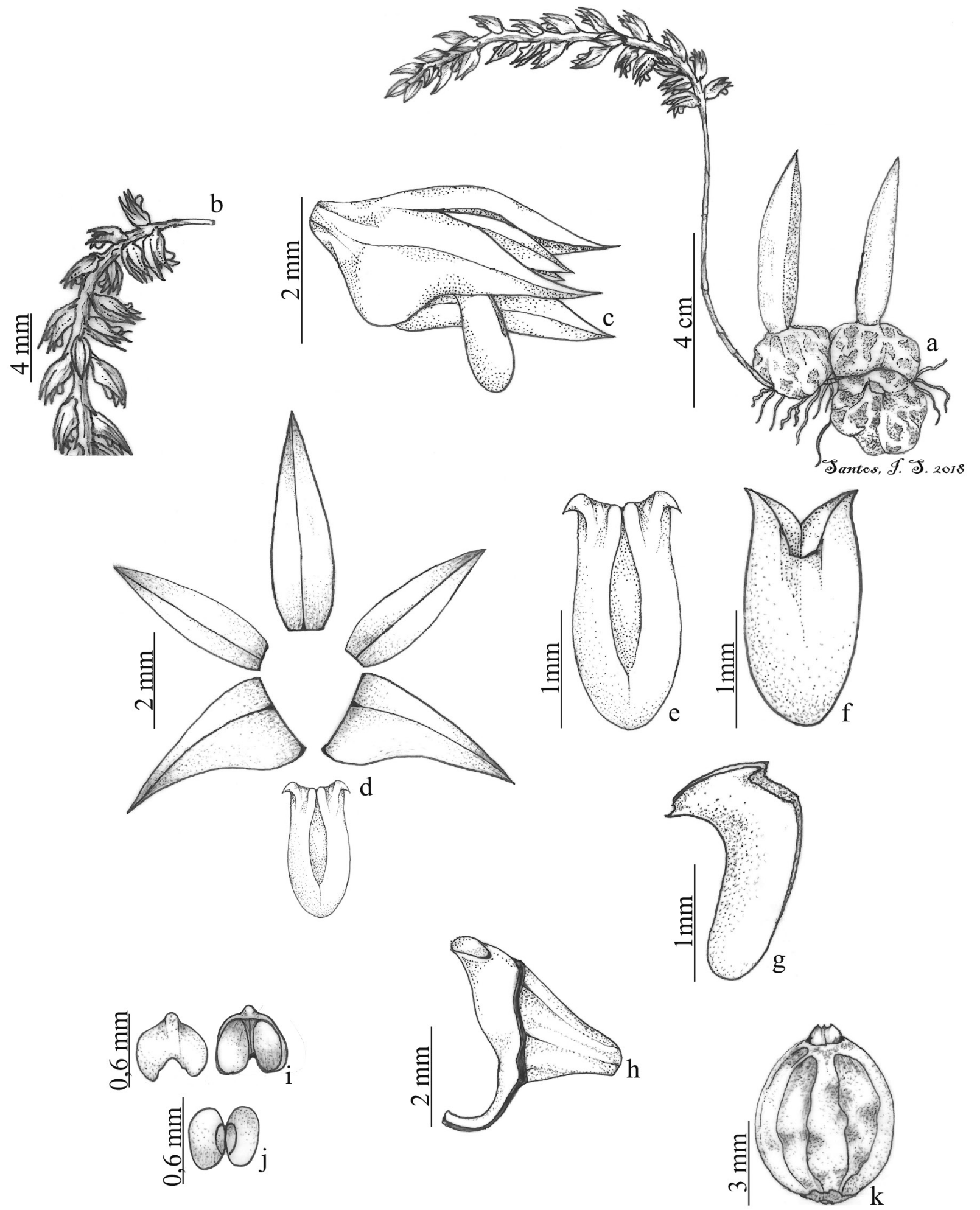

Figura 7. Bulbophyllum rupicolum Barb. Rodr. a. Hábito. b. Detalhe da inflorescência. c. Flor em vista lateral. d. Peças florais dissecadas. e. Labelo em vista frontal. f. Labelo em vista dorsal. g. Labelo em vista lateral. h. Coluna. i. Antera em vista dorsal e ventral. j. Polínias. k. Cápsula. (I.S. Santos et al. 378).

Figure 7. Bulbophyllum rupicolum Barb. Rodr. a. Habit. b. Detail of inflorescence. c. Flower, side view. d. Floral pieces dissected. e. Lip, frontal view. f. Lip, dorsal view. g. Lip, side view. h. Column. i. Anther, dorsal and ventral view. j. Pollinia. k. Capsule. (I.S. Santos et al. 378). 

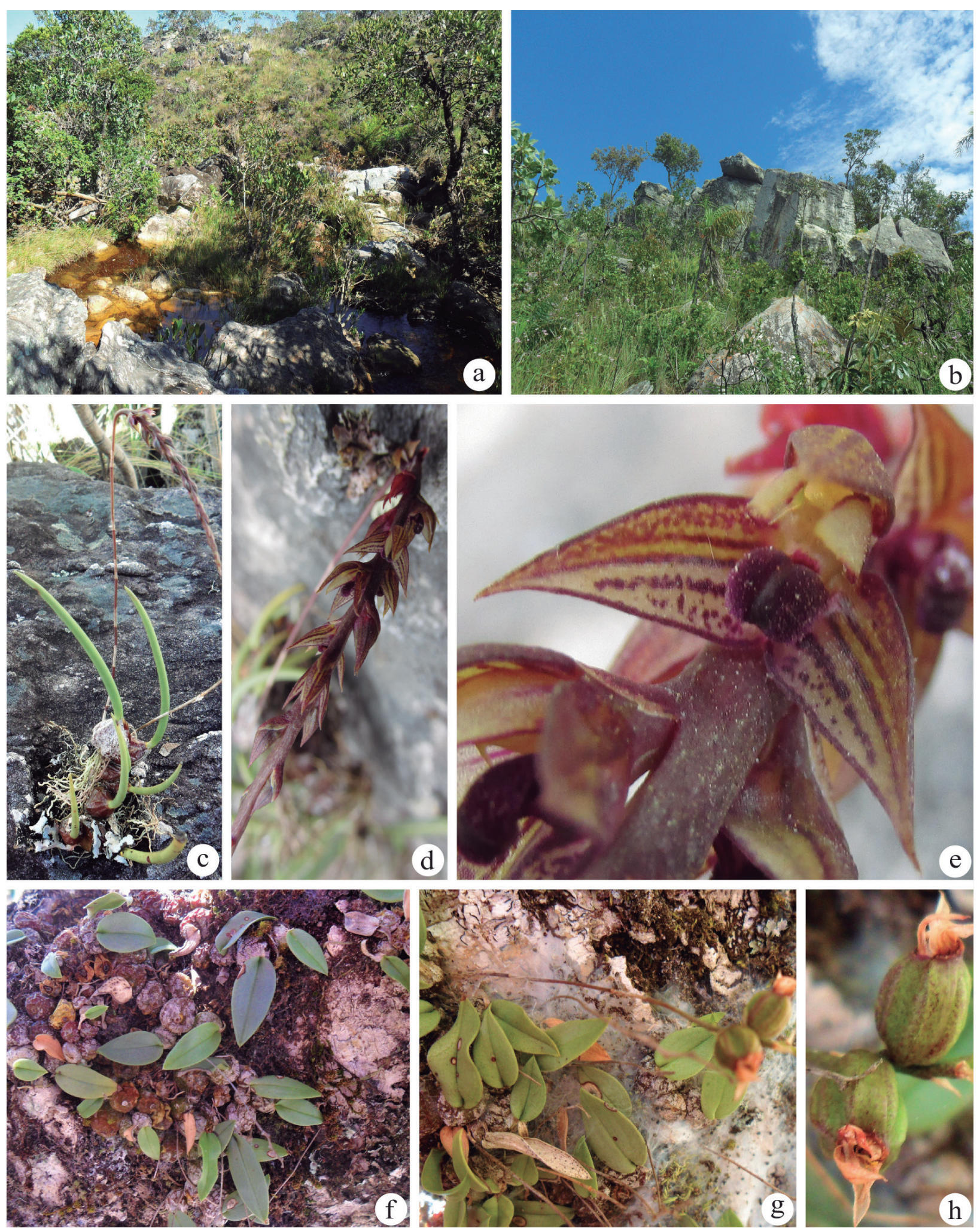

Figura 8. a, b. Habitats. a. Mata de galeria. b. Cerrado rupestre. c-e. Bulbophyllum adiamantinum. c. Hábito. d. Detalhe da inflorescência. e. Flor. f-h. Bulbophyllum ciluliae. f-g. Hábito. h. Cápsulas.

Figure 8. a, b. Habitats. a. Gallery forest. b. Rocky field. c-e. Bulbophyllum adiamantinum. c. Habit. d. Detail of inflorescence. e. Flower. f-h. Bulbophyllum ciluliae. f-g. Habit. h. Capsules. 

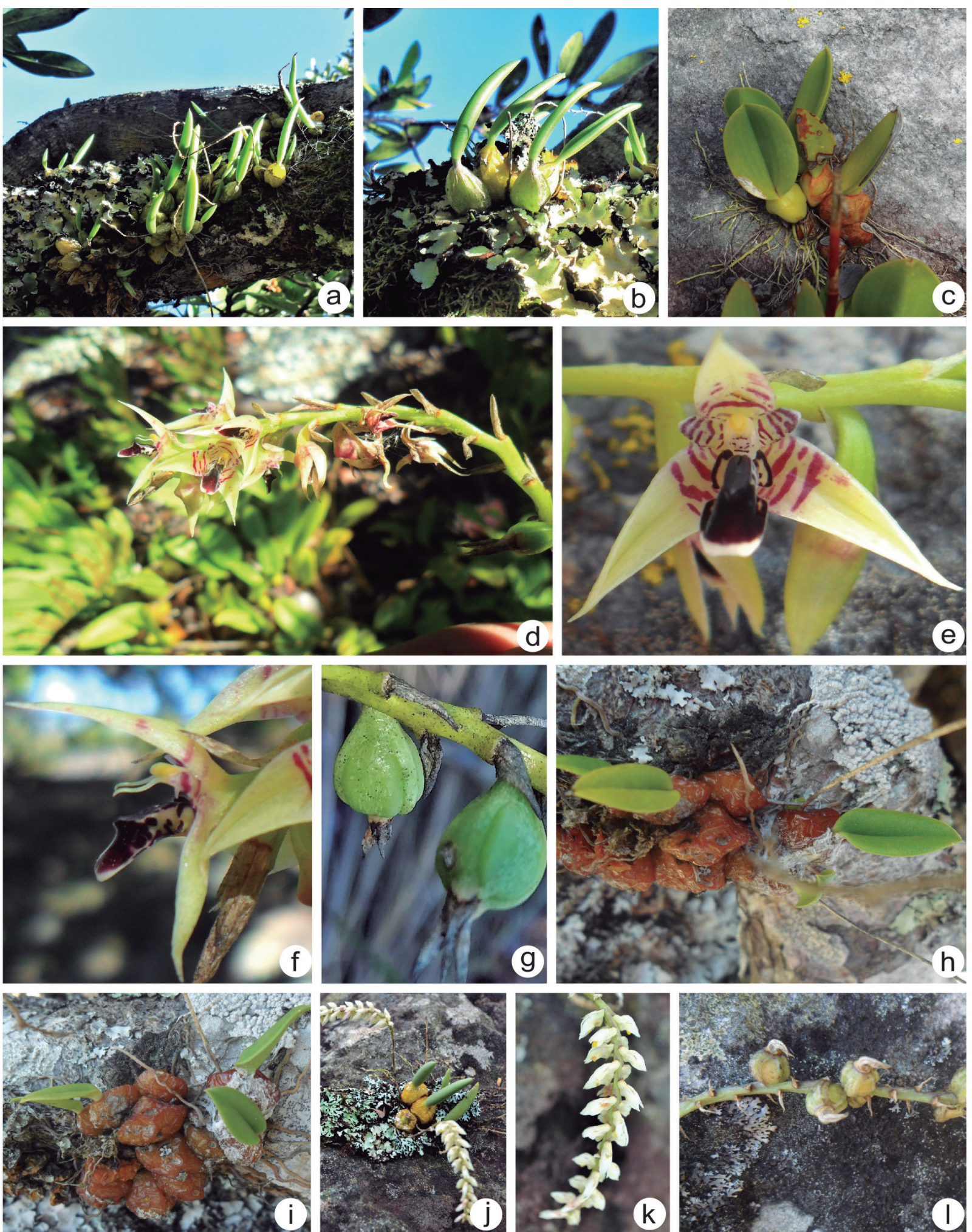

Figura 9. a, b. Bulbophyllum epiphytum (hábito). c-g. Bulbophyllum exaltatum. c. Hábito. d. Detalhe da inflorescência. e. Flor em vista frontal. f. Flor em vista lateral. g. Cápsulas. h-i. Bulbophyllum plumosum (hábito). j-1. Bulbophyllum rupicolum. j. Hábito. k. Detalhe da inflorescência. 1. Cápsulas.

Figure 9. a, b. Bulbophyllum epiphytum (habit). c-g. Bulbophyllum exaltatum. c. Habit. d. Detail of inflorescence. e. Flower, frontal view. f. Flower, side view. g. Capsules. h-i. Bulbophyllum plumosum (habit). j-1. Bulbophyllum rupicolum. j. Habit. k. Detail of inflorescence. 1. Capsules. 
próximo ao bueiro, ca. de $500 \mathrm{~m}$, próximo ao Morro do Japonês, 27-I-2018, fl., I.S. Santos et al. 378 (UFG); idem, 28-IV-2018, fr., I.S. Santos et al. 464 (UFG).

Material examinado adicional: BRASIL. 18-X-1869, fl., fr., Regnell, III-1138 (P); GoIÁs: Alto Paraíso de Goiás, Chapada dos Veadeiros, rooted in soil - filled depression, burned - over campo ca. $7 \mathrm{~km}$, W. of Veadeiros, $14^{\circ} \mathrm{S}, 47^{\circ} \mathrm{W}, 950 \mathrm{~m}, 15-\mathrm{II}-1966$, fl., fr., H.S. Irwin et al. 12911 (NY); Pirenópolis, Área do Morro do Cabeludo, em afloramentos rochosos e campo limpo úmido circundante, 17-I-1992, fl., fr., J.A.N. Batista 234 (CEN); Estrada Velha PirenópolisCocalzinho, a $15 \mathrm{~km}$ de Pirenópolis, próximo das torres de transmissão, em afloramentos de arenito, 22-II-1993, fl., L. Bianchetti 1471 (CEN); Parque Estadual da Serra dos Pireneus, lado direito da estrada de terra que sai de Pirenópolis e vai para Cocalzinho, atravessando o parque, próximo ao Morro do Cabeludo, em afloramento rochoso, 16-III-2002, fl., K.F. Pellizzaro \& D.S. Diniz 11 (CEN); Serra Dourada, nos rochedos, I-1893, fl., E. Ule 499 (P); Minas GeraIs: Caldas, 1868, fl,. S.E. Henschen 1138 (US).

Espécie endêmica do Brasil (GO, MT, MG, SP e PR), (Smidt 2007, BFG 2015). No PNCV foi encontrada como rupícola, em afloramentos rochosos, ou epífita, em matas de galeria. Floresce e frutifica entre agosto e janeiro. Pode ser confundida com B. epiphytum por ambas compartilharem de folhas cilíndricas, sulcadas longitudinalmente, pseudobulbos verde-amarelados e flores brancas com labelo amarelo (Smidt 2007). No entanto, em B. rupicolum as folhas são curvadas (vs. eretas), pseudobulbos globosos (vs. piriformes), pétalas elíptico-lanceoladas, com nervura central vinácea (vs. lanceoladas, não vinácea), margem não papilosa (vs. papilosa); e labelo mais largo na base do que em sua porção distal (vs. mais largo em sua porção distal do que basal), com $2 \times 0,7-1 \mathrm{~mm}$, (vs. labelo $3-4 \times 1,1-1,2 \mathrm{~mm}$ ) e região basal paralela à coluna com margem inteira ( $v s$. margem serrilhada).

\section{Agradecimentos}

Ao Instituto Chico Mendes da Biodiversidade, ICMBio pela permissão de coletas no Parque Nacional da Chapada dos Veadeiros, através do Projeto "Levantamento Florístico do Parque Nacional da Chapada dos Veadeiros, Goiás, Brasil”, financiado pelo CNPq (proc. no. 445669/2014-4), a esta última
Instituição pela bolsa de Iniciação Científica concebida ao primeiro autor e a Universidade Federal de Goiás pela disponibilidade de transportes e instalações.

\section{Literatura citada}

Bianchetti, L.B. \& Batista, J.A.N. 2004. Bulbophyllum ciluliae (Orchidaceae): uma nova espécie para o Bioma Cerrado, Brasil, Sitientibus série Ciências Biológicas. 4: $20-24$.

BFG (The Brazil Flora Group). 2015. Growing knowledge: an overview of Seed plants diversity in Brazil. Rodriguésia 66: 1085-1113.

Brade, A.C. 1951. Orchidaceae Novae Brasilienses. VII. Arquivos do Jardim Botânico do Rio de Janeiro 11: 79-85.

Campacci, M. 2009. Coletânea de orquídeas brasileiras 7: novas espécies. Editora Brasil Orquídeas. São Paulo. São Paulo.

Campacci, M. 2010. Coletânea de orquídeas brasileiras 8: novas espécies. Editora Brasil Orquídeas. São Paulo. São Paulo.

Chiron, G.R. \& Castro Neto, V.P. 2009. Contribution à la connaissance des orchidées 90 du Brésil. XVI: une nouvelle espèce de Bulbophyllum de l'Espírito Santo, Richardiana 9: 70-75.

Frodin, D.G. 2004. History and concepts of big plant genera. Taxon 53: 753-776.

Gravendeel, B., Vermeulen, J.J., Fisher, G.A., Smidt, E.C., Veitch, N.C., Grayer, R.J. \& Sieder, A. 2014. 621. Bulbophyllum. In: A.M. Pridgeon, P.J. Cribb, M.W. Chase \& F.N. Rasmussen (eds.) Genera Orchidacearum, 6, Epidendroideae (Part Three). Oxford University, Oxford, pp. 4-51.

Hall, C.F., Klein, V.L.G. \& Barros, F. 2013. Orchidaceae no município de Caldas Novas, Goiás, Brasil, Rodriguésia 64: 685-704.

Felfili, J.M., Rezende, A.V. \& Silva Júnior, M.C. 2007. Biogeografia do Bioma Cerrado: vegetação e solos da Chapada dos Veadeiros. Brasília, Editora Universidade de Brasília/Finatec.

Mancinelli, W.S. \& Smidt, E.C. 2012. O gênero Bulbophyllum (Orchidaceae) na Região Sul do Brasil, Rodriguésia 63: 803-815.

Mancinelli, W.S. 2011. Levantamento de espécies sul-brasileiras do gênero Bulbophyllum Thouars (Orchidaceae, Dendrobieae). Dissertação de Mestrado, Universidade Federal do Paraná, Curitiba.

Mendonça, R.C., Filgueiras, T.S. \& Fagg, C.W. 2007. Análise florística da Chapada dos Veadeiros. In: J.M. Felfili, A.V. Rezende, M.C. Silva Júnior (orgs.). Biogeografia do Bioma Cerrado: vegetação e solos da Chapada dos Veadeiros. Editora Universidade de Brasília. Finatec. Brasília. pp. 121-192. 
Mori, S.A., Silva, L.A., Lisboa, G. \& Coradin, L. 1989. Manual de Manejo do Herbário Fanerogâmico. 2 ed. CEPLAC, Ilhéus.

Mota, R.C., Barros, F. \& Stehmann, J.R. 2009. Two new species of Orchidaceae from Brazil: Bulbophyllum carassense and Lephanthopsis vellozicola, Novon 19: 380-387.

Munhoz, C.B.R \& Proença, C.E.B. 2008. Composição florística do Município de Alto Paraíso de Goiás na Chapada dos Veadeiros, Boletim do Herbário Ezechias Paulo Heringer 3: 102-150.

Ribeiro P.L. 2006. Variabilidade genética e morfológica intra e interpopulacional no complexo Bulbophyllum exaltatum (Orchidaceae) ocorrente nos campos rupestres: implicações taxonômicas e biogeográficas. Dissertação de Mestrado, Universidade Estadual de Feira de Santana, Feira de Santana.

Sieder, A., Rainer, H. \& Kiehn, M. 2007. Checklist for Bulbophyllum and allied taxa (Orchidaceae). Botanical Garden, University of Vienna. Disponível em http:// www.cites.org/common/com/NC/tax ref/Bulbophyllum (acesso em 31-VIII-2018).
Smidt, E.C. 2007. Filogenia e revisão taxonômica de Bulbophyllum Thouars (Orchidaceae) ocorrentes no neotrópico. Tese de Doutorado, Universidade Estadual de Feira de Santana, Feira de Santana.

Smidt, E.C.\& Borba, E.L. 2007. Bulbophyllums in Brazil: collection history and distribution. Orchids 76: 130-133.

Smidt, E.C. \& Borba, E.L. 2008. A new species of Bulbophyllum Thouar (Orchidaceae) from Minas Gerais, Brazil, Revista Brasileira de Botânica 31: 453-456.

Smidt, E.C. \& Borba, E.L. 2009. Two new species of Bulbophyllum (Orchidaceae) from Brazil, Novon 19: 122-126.

Thiers, B. (continuously updated). 2018. Index Herbariorum. Part I: The herbaria of the world. New York Botanical Garden. Disponível em from http:// sweetgum. nybg.org/science/ih/ (acesso em 31-VII-2018).

Vermeulen, J.J. 2014. Bulbophyllum In: A.M. Pridgeon, P.J. Cribb, M.W. Chase \& F.N. Rasmussen (ed.). Genera orchidacearum, Epidendroideae. Oxford University Press, New York, Part 3, v. 6, pp. 451.

Verola, C.F. 2002. Biologia floral e sistemas de reprodução em espécies de Bulbophyllum (Orchidaceae) ocorrentes em mata de galeria, campo rupestre e floresta estacional. Dissertação de Mestrado, Universidade Estadual de Campinas, Campinas. 